\title{
Pengaruh Peningkatan Tekanan Darah terhadap Memori Jangka Pendek pada Pralansia di Kota Depok
}

\author{
Ria Maria Theresa \\ Program Studi Profesi Dokter, FK UPN Veteran Jakarta \\ Jl. RS Fatmawati, Pondok Labu, Kec. Cilandak, Depok, Jawa Barat 12450 \\ Email : ria.maria@upnvj.ac.id
}

\begin{abstract}
ABSTRAK
Tekanan darah yang meningkat atau hipertensi dapat berakibat terhadap kerusakan pada endotel pembuluh darah di otak. Hal tersebut merupakan faktor risiko terjadinya penurunan fungsi memori pada pralansia. Penurunan fungsi memori yang diakibatkan peningkatan tekanan darah dapat memengaruhi aktifitas dan kualitas hidup pada pralansia. Penelitian ini bertujuan untuk melihat pengaruh peningkatan tekanan darah terhadap memori jangka pendek pada pralansia di Depok. Penelitian analitik dengan teknik potong lintang, jumlah sampel sebanyak 138 orang, usia 45-59 tahun, pengambilan sampel menggunakan teknik consecutive sampling. Data dianalisis dengan uji Spearman. Hasil analisis menunjukkan adanya pengaruh antara peningkatan tekanan darah dengan tes Digit Span Backward dengan kekuatan korelasi lemah $(\mathrm{p}=0,001$ dan $\mathrm{r}=0,273)$, tidak ada pengaruh antara peningkatan tekanan darah dengan tes Digit Span Forward $(\mathrm{p}=0,137$ dan $\mathrm{r}=-0,127)$. Fungsi memori jangka pendek penting dipertahankan oleh para pralansia agar aktivitas sehari-hari dapat terlaksana dengan baik dan para pralansia tetap mandiri.
\end{abstract}

Kata Kunci: Tekanan darah, memori jangka pendek, pralansia

\begin{abstract}
Increasing blood pressure or hypertension will cause damage to the endothelial blood vessels in the brain. Hypertension is a risk factor for decreasing memory function in pre elderly. High blood pressure which has impact on memory function can affect the activity and quality of life in pre elderly. The purpose of this study was to determine the effect of increased blood pressure on short-term memory in pre elderly in Depok. This is analytical study with a cross-sectional technique. The number of subject is 138 subject, age 45-59 years, with consecutive technique sampling. Data were analyzed by Spearman test. This study showed that there was a relationship between the increasing in blood pressure and the Digit Span Backward test with a weak correlation strength $(\mathrm{p}=0.001$ and $\mathrm{r}=0.273)$, there was no effect between increasing blood pressure with the Digit Span Forward test $(p=0.137$ and $r=-0.127)$. It is very important to maintain short term memory in pre elderly so the elderly can carry out daily activities and live independently.
\end{abstract}

Keywords: Blood pressure, short-term memory, pre elderly 


\section{Pendahuluan}

Hipertensi adalah suatu keadaan dimana seseorang akan mengalami peningkatan tekanan darah di atas normal. Hal ini akan mengakibatkan peningkatan angka kesakitan (morbiditas) dan angka kematian (mortalitas). ${ }^{1,2}$ Peningkatan tekanan darah yang berlangsung cukup lama akan berdampak terhadap peningkatan tekanan pembuluh darah yang menetap/persisten. Tekanan darah pada dewasa normal adalah $120 \mathrm{mmHg}$ yaitu ketika jantung berdenyut (sistolik) dan tekanan darah ketika jantung relaksasi (diastolik) adalah 80 mmHg. Ketika tekanan sistolik sama dengan atau lebih dari $140 \mathrm{mmHg}$ dan/atau tekanan diastolik sama dengan atau lebih dari 90 mmHg maka dinyatakan bahwa tekanan darah meningkat atau hipertensi. ${ }^{2}$

Menurut Joint National Committe on Prevention, Detection, Evaluation, and Treatment of High Blood Pressure, tekanan darah yang tinggi akan membahayakan nyawa seseorang karena jantung bekerja terlalu keras dan dapat menyebabkan terjadinya pengerasan pembuluh darah (aterosklerosis). ${ }^{3}$ Tekanan darah yang meningkat merupakan faktor risiko terjadinya penyakit jantung dan strok. Hal itu merupakan penyebab pertama dan ketiga kematian di Amerika Serikat. Tekanan darah yang meningkat akan menyebabkan kerusakan organ lain, seperti gagal jantung kongestif, penyakit ginjal dan lain-lain. ${ }^{4}$

Prevalensi peningkatan tekanan darah/hipertensi di Indonesia pada kelompok usia $\geq 18$ tahun sebanyak $26,5 \%$. Sebagian besar $(63,2 \%)$ kasus peningkatan tekanan darah di masyarakat sering sulit didiagnosis karena ketidaktahuan masyarakat tentang penyakit hipertensi. Jawa Barat menjadi urutan ke-4 tertinggi kemudian diikuti oleh Bangka Belitung, Kalimantan Selatan dan Kalimantan Timur dengan presentase hipertensi sebesar $29,4 \% .^{5}$ Pada tahun 2008 di unit rawat jalan Puskesmas Kota Depok terdapat 18,089 kasus baru hipertensi esensial $(10,01 \%)$ antara usia 45-64 tahun. ${ }^{5}$

Peningkatan tekanan darah akan memengaruhi fungsi kognitif seseorang. Fungsi kognitif yang dipengaruhi yaitu memori jangka pendek. Pasien yang memiliki riwayat tekanan darah tinggi yang tidak terkontrol kemungkinan akan menunjukkan lebih banyak penurunan fungsi kognitif daripada yang terkontrol.

Memori jangka pendek (short term memory) bersifat terbatas dalam kapasitas dan durasi. Informasi akan hilang dalam 20-30 detik apabila informasi tidak ulang-ulang. Memori jangka pendek sangat penting karena diperlukan untuk menyelesaikan sebagaian besar dari tugas kognitif yang digunakan sebagai memori kerja untuk menjaga dan memanipulasi suatu informasi. Memori jangka pendek digunakan untuk menyimpan informasi baru termasuk rincian, seperti siapa, apa, kapan dan dimana. ${ }^{6}$

Gangguan pada memori jangka pendek dapat menyebabkan kesulitan untuk dapat mengikuti suatu percakapan atau melakukan suatu kegiatan yang kompleks seperti menjalankan bisnis atau mengelola kelas atau reuni keluarga. ${ }^{6}$

Seiring bertambahnya usia, seseorang akan mengalami penurunan daya ingat, dimana 
hal ini sering dianggap sebagai sebagai suatu hal yang normal pada proses penuaan. Pada dekade keenam dalam kehidupan, sebagian orang akan mengalami penurunan daya ingat ringan, dan kelompok usia yang lebih tua, akan terjadi penurunan daya ingat yang lebih serius. Prevalensi penurunan fungsi memori pada pertambahan usia adalah $41 \%$ untuk orang yang berusia $50-59$ tahun dan $52 \%$ bagi mereka yang berusia 60-69 tahun. ${ }^{7}$ Penelitian ini penting untuk dilakukan untuk melihat dampak peningkatan tekanan darah terhadap memori jangka pendek pada pralansia agar dapat dilakukan pencegahan sejak awal.

\section{Metode Penelitian}

Penelitian ini merupakan penelitian deskriptif analitik dengan teknik potong lintang, ${ }^{8,9}$ Penelitian ini mengukur dan menganalisis variabel bebas yaitu peningkatan tekanan darah/hipertensi dengan variabel terikat yaitu fungsi memori jangka pendek yang diukur menggunakan tes Digit Span pada orang dengan peningkatan tekanan darah/hipertensi usia 45-59 di Depok. ${ }^{10}$ Populasi dalam penelitian adalah pasien yang mengalami peningkatan tekanan darah/hipertensi di Depok, tahun 2016. Sampel pada penelitian ini adalah pasien dengan peningkatan tekanan darah/hipertensi usia 4559 tahun di Depok. Teknik pengambilan sampel berdasarkan non probability sampling yang memiliki kriteria tertentu untuk sampelnya, yaitu consecutive sampling. ${ }^{8.9}$ Jumlah sampel sebanyak 138 subyek. Analisa data menggunakan Uji Spearman.

\section{Hasil}

Pada tabel 1 dapat dilihat bahwa sebanyak 138 subyek mengalami peningakatan tekanan darah/hipertensi usia 45-59 tahun, subyek laki-laki berjumlah 39 orang dan subyek perempuan berjumlah 99 orang. Karakteristik usia subyek penelitian didapatkan dengan rentang usia 45-50 tahun berjumlah 59 subyek, usia 51-55 tahun berjumlah 47 subyek, dan usia 56-59 tahun berjumlah 32 subyek. Gambaran peningakatan tekanan darah/hipertensi yaitu sebanyak 96 subyek dikategorikan sebagai hipertensi ringan, 25 subyek dikategorikan sebagai hipertensi sedang dan 17 subyek dikategorikan sebagai hipertensi berat.

Tabel 1. Karakteristik Subyek

\begin{tabular}{|c|c|c|}
\hline Karakteristik & Jumlah (n) & $\%$ \\
\hline \multicolumn{3}{|l|}{ Jenis Kelamin } \\
\hline Laki-laki & 39 & 28,3 \\
\hline Perempuan & 99 & 71,7 \\
\hline \multicolumn{3}{|l|}{ Usia } \\
\hline 45-50 tahun & 59 & 42,8 \\
\hline $51-55$ tahun & 47 & 32,1 \\
\hline 56-59 tahun & 32 & 23,2 \\
\hline \multicolumn{3}{|l|}{ Hipertensi } \\
\hline $\begin{array}{l}\text { Ringan (140/90- } \\
159 / 99)\end{array}$ & 96 & 69,6 \\
\hline $\begin{array}{l}\text { Sedang (160/100- } \\
179 / 109)\end{array}$ & 25 & 18,1 \\
\hline Berat $(\geq 180 / 110)$ & 17 & 12,3 \\
\hline Total & 138 & $\overline{100}$ \\
\hline
\end{tabular}

Pada hasil tes Digit Span Forward didapatkan nilai mean sebesar 5,47 dengan nilai median 6 dan pada hasil tes Digit Span Backward didapatkan nilai mean sebesar 3,42 dengan nilai median 3 . 
Tabel 2. Persentase nilai Digit Span Forward dan Digit Span Backward

\begin{tabular}{ccc}
\hline Digit Span & Jumlah (n) & \% \\
\hline Forward (digit) & & \\
3 digit & 2 & 1.4 \\
4 digit & 28 & 20.3 \\
5 digit & 29 & 21.0 \\
6 digit & 37 & 26.8 \\
7 digit & 29 & 21.0 \\
8 digit & 13 & 9.4 \\
Backward & & \\
(digit) & & \\
0 digit & 2 & 1.4 \\
2 digit & 41 & 29.7 \\
3 digit & 46 & 33.3 \\
4 digit & 19 & 13.8 \\
5 digit & 25 & 18.1 \\
6 digit & 3 & 2.2 \\
7 digit & 2 & 1.4 \\
\hline Total & 138 & 100 \\
\hline
\end{tabular}

Analisis bivariat pada tabel 3 menggunakan uji korelasi Spearman didapatkan nilai $\mathrm{p} 0,137$ ( $\mathrm{p}>0,05)$ untuk hipertensi dengan Digit Span Forward dengan arah korelasi negatif, yang menunjukkan tidak ada pengaruh antara hipertensi dengan tes Digit Span Forward. Selain itu didapatkan juga nilai $\mathrm{p} 0,001(\mathrm{p}<0,05)$ untuk hipertensi dengan Digit Span Backward dengan arah korelasi positif dan kekuatan korelasi lemah, yang menunjukkan adanya pengaruh antara hipertensi dengan tes Digit Span Backward.

Tabel 3. Hasil uji korelasi Spearman (Digit Span Forward)

\begin{tabular}{lcc}
\hline Digit Span Forward & & \\
\hline Hipertensi & $\mathrm{r}$ & $-0,127$ \\
& $\mathrm{p}$ & 0,137 \\
& $\mathrm{n}$ & 138 \\
Digit Span Backward & & \\
Hipertensi & $\mathrm{r}$ & 0,273 \\
& $\mathrm{p}$ & 0,001 \\
& $\mathrm{n}$ & 138 \\
\hline
\end{tabular}

Berdasarkan uji Spearman yang digunakan untuk mencari hubungan antara hipertensi dengan fungsi memori jangka pendek. Pada uji korelasi hipertensi dengan Digit Span Forward nilai $\mathrm{p}=0,137$, yang artinya tidak terdapat hubungan antara hipertensi dengan tes Digit Span Forward. Untuk Digit Span Backward didapatkan nilai $\mathrm{p}=0,001$, yang menandakan terdapat hubungan antara hipertensi dengan tes Digit Span Backward dengan kekuatan korelasi yang lemah dan arah korelasi yang positif.

\section{Pembahasan}

Menurut teori yang ada bahwa hipertensi juga berhubungan dengan gangguan kognitif terutama pada kelompok usia lanjut. Hipertensi jangka panjang/lama akan berdampak terhadap penurunan fungsi kognitif yang terjadi pada usia pertengahan dan usia lanjut. Pada penyandang hipertensi juga memiliki risiko terjadinya demensia vaskular yang diakibatkan karena adanya infark pada pembuluh darah. ${ }^{1,2,3}$

Selain itu beberapa penelitian menjelaskan bahwa penurunan fungsi kognitif ini meliputi gangguan memori, atensi, mengukur jarak dan yang paling membahayakan adalah adanya gangguan pada fungsi eksekutif. Apabila fungsi eksekutif terganggu akan menyebabkan ketidak mampuan seseorang untuk memulai, mengorganisasikan dan mengambil keputusan.

\section{Kesimpulan dan Saran}

Penelitian ini menunjukkan sebanyak 71,7\% subyek penelitian adalah perempuan. Subyek berusia 45-50 tahun sebanyak $42,8 \%$. Jumlah subyek dengan hipertensi ringan sebanyak 69,6\%, hipertensi sedang sebanyak $18,1 \%$ dan hipertensi berat sebanyak $12,3 \%$. 
Sebanyak $26,8 \%$ subyek mampu mengingat 6 digit angka untuk digit span forward dan $29,9 \%$ subyek mampu mengingat 2 digit angka untuk digit span backward.

Penelitian ini membuktikan adanya pengaruh peningkatan tekanan darah/hipertensi terhadap fungsi memori jangka pendek pada pralansia di Depok. Hal-hal yang dapat memengaruhi peningkatan tekanan darah seperti waktu tidur, kebiasaan merokok, diet yang salah, serta stres dapat memengaruhi fungsi memori sehingga agar memori dapat dipertahankan dengan optimal maka perlu dilakukan kegiatan yang bisa mempertahankan fungsi memori.

\section{Ucapan Terima Kasih}

Penulis mengucapkan terima kasih kepada para subyek penelitian atas partisipasinya dalam penelitian ini.

\section{Daftar Pustaka}

1. Dalimartha, S. et al, (2008). Care Your Self Hipertensi. Jakarta: Penebar Plus +.

2. Dreisbach, Albert W. (2013) Epidemiology of Hypertension [online]. Available from: http://emedicine.medscape.com/article/192 8048-overview\#aw2aab6b5 (Accessed 1 June 2014)

3. Joint National Comitte on Prevention, Detection, Evaluation, and Treatment of High Blood Pressure. 2003. Seventh Report of The Joint National Committe on Prevention, Detection, Evaluation, and Treatment of High Blood Pressure JNC Express (NIH Publication No.03-5233).
Bethesda, MD:U.S.Department of Health and Human Services.

4. WHO (2013). Q\&As on hypertension [online]. Available from: http://www.who.int/features/qa/82/en/ (Accessed 20 August 2014)

5. Profil Kesehatan Indonesia 2014, Kementerian Kesehatan Indonesia, 2015

6. Doty, L. (2007) Mild Cognitive Impairment. Fla. Dep. Elder Aff. Alzheimer's Dis. Initiat.

7. Small, G.W., La Rue, A., Komo, S., Kaplan, A., Mandelkern, M.A., 1995. Predictors of Cognitive Change in middleAged and Older Adul. Am. J. Psychiatry 152, 1757.

8. Dahlan, M. S. (2011). Statistik Untuk Kedokteran Dan Kesehatan (5th ed.). Jakarta: Salemba Medika.

9. Sastroasmoro, S. 2011. Dasar-dasar Metodologi Penelitian Klinis. Edisi ke-4. Jakarta: Binarupa Aksara

10. St Clair-Thompson, H.L., Allen, R.J., 2013. Are forward and backward recall the same? A dual-task study of digit recall. Mem. Cognit. 41, 519-532. doi:10.3758/s13421-012-0277-2 